\title{
ANALYSIS OF IMPACT ENERGY TO FRACTURE UNNOTCHED CHARPY SPECIMENS MADE FROM RAILROAD TANK CAR STEEL
}

\author{
H. Yu \\ Chenga Advanced Solutions \& Engineering, LLC \\ Cambridge, Massachusetts USA \\ J.E. Gordon \\ Volpe National Transportation Systems Center \\ Cambridge, Massachusetts USA
}

\author{
D.Y. Jeong \\ Volpe National Transportation Systems Center \\ Cambridge, Massachusetts USA \\ Y.H. Tang \\ Volpe National Transportation Systems Center \\ Cambridge, Massachusetts USA
}

\begin{abstract}
This paper describes a nonlinear finite element analysis (FEA) framework that examines the impact energy to fracture unnotched Charpy specimens by an oversized, nonstandard pendulum impactor called the Bulk Fracture Charpy Machine (BFCM). The specimens are made from railroad tank car steel, have different thicknesses and interact with impact tups with different sharpness. The FEA employs a Ramberg-Osgood equation for plastic deformations. Progressive damage and failure modeling is applied to predict initiation and evolution of fracture and ultimate material failure. Two types of fracture initiation criterion, i.e., the constant equivalent strain criterion and the stress triaxiality dependent equivalent strain criterion, are compared in material modeling. The impact energy needed to fracture a BFCM specimen is calculated from the FEA. Comparisons with the test data show that the FEA results obtained using the stress triaxiality dependent fracture criterion are in excellent agreement with the BFCM test data.
\end{abstract}

\section{INTRODUCTION}

The loss of lading from railroad tank cars involved in accidents is commonly caused by failures in three general locations: (1) tank end cap or head, (2) side of the tank or shell, and (3) damage to fittings and valves. Failures in the tank car head and shell occur from collisions with objects, such as couplers and wheels from adjacent cars, broken rails, etc.

Research is ongoing within the government and the industry to improve the safety of railroad tank cars carrying hazardous materials (hazmat). Scaled and full-scale impact testing have been performed in the past to examine the puncture resistance of railroad tank cars [1-2], but the mechanics of material failure under such loading conditions are not well understood. Moreover, no industry-accepted standard currently exists to quantify the puncture behavior of materials.

In this paper, a nonlinear finite element analysis (FEA) approach is described that examines the fracture of unnotched specimens subjected to pendulum impact loading. Different material failure criteria are used in conjunction with the nonlinear FEA to simulate the tests and to calculate fracture energy. The criteria are based on the state of stress and strain in the impacted specimen. Moreover, a failure criterion based on stress triaxiality, which is a parameter related to the state of stress, provides excellent agreement with the test data for fracture energy.

\section{PENDULUM IMPACT TESTING}

Previous research to examine the resistance of tank car steels to impact loading has focused on fracture toughness or Charpy V-notch (CVN) energy. Industry-accepted procedures exist to conduct these types of tests, which use specimens containing a pre-existing crack (usually fatigue-sharpened) or a stress concentration or notch. However, the physical significance of fracture toughness or impact energy in a structure without a pre-existing crack is unclear.

Pendulum impact testing, such as the standard CVN test, has been used to examine the impact resistance of materials for over a century because it is relatively simple, inexpensive, and rapid to perform [3]. In addition, the physical interpretation of the test is clear. The energy available to fracture the specimen is proportional to the initial height of the swing hammer above a reference level ( $y_{1}$ in Figure 1). The energy remaining in the hammer is characterized by the height to which it recovers $\left(y_{2}\right)$, and the weight of the striker times the difference $\left(y_{1}-y_{2}\right)$ represents the energy absorbed by the specimen. The physics of the pendulum test are the same whether the specimen

This material is declared a work of the U.S. Government and is not subject to copyright protection in the United States. Approved for public release; distribution is unlimited. 
contains a notch or not. However, more energy is needed to fracture an unnotched specimen compared to one containing a notch.

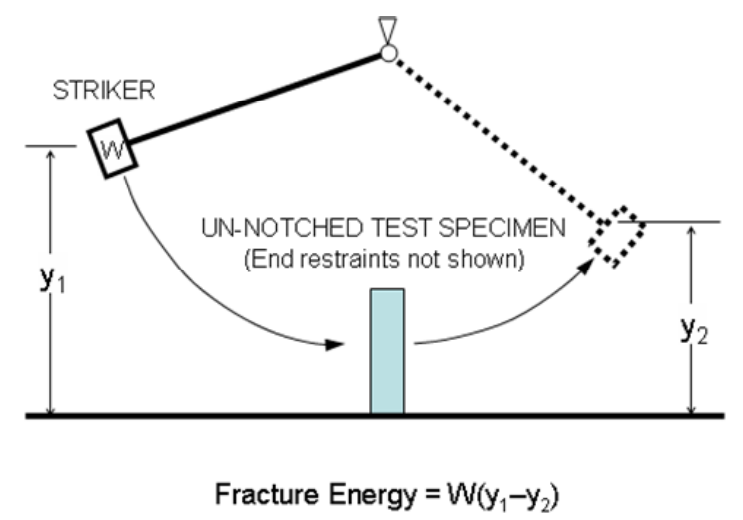

Figure 1. Schematic of Pendulum Impact Test

An oversized, nonstandard pendulum impactor was built by Southwest Research Institute (SwRI) to examine the fracture energy of different tank car steels (see Figure 2). The size of the fixture was necessary in order to achieve the levels of energy needed to fracture the unnotched specimens. This pendulum test fixture, called the Bulk Fracture Charpy Machine (BFCM), was constructed specifically to conduct studies to assess puncture behavior. That is, the measurement of fracture energy is used to assess the puncture resistance of tank car steel.

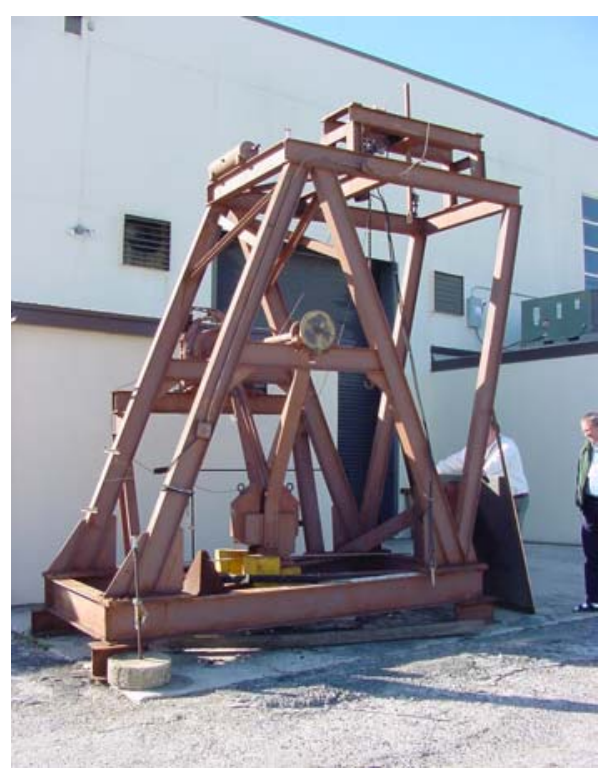

Figure 2. Oversized, Nonstandard Pendulum Impactor
Figure 3 shows a drawing of a BFCM test specimen. The trapezoidal ends of the specimen self-engage into the test fixture, so they are held fixed as the impact load is applied through the pendulum. In this drawing, the test section is 6 inches long, and the specimen width is 1 inch.

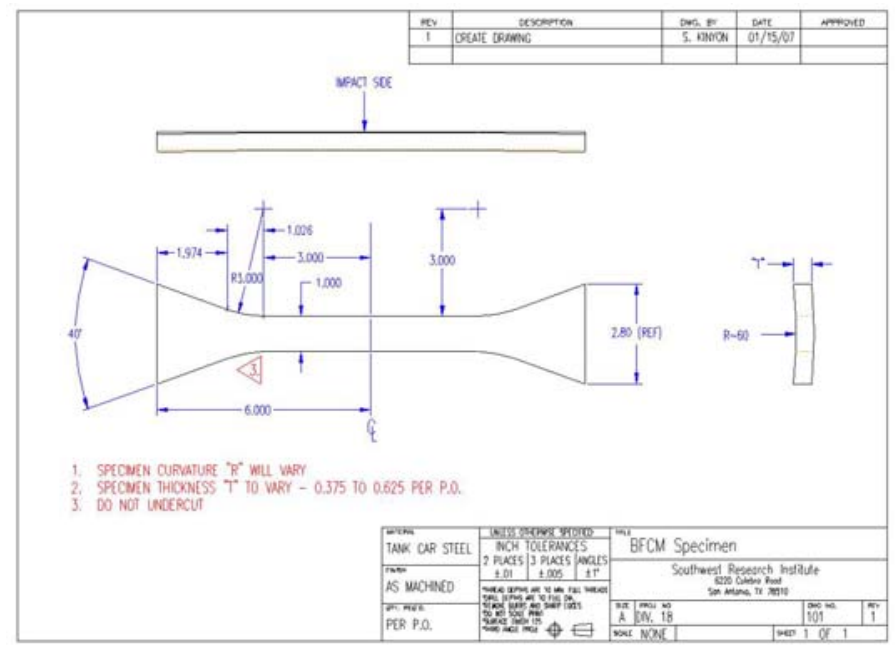

Figure 3. BFCM Test Specimen

Two batches of normalized TC128-B steel were used in the tests, and are identified as Materials 1 and 2 in Table 1 with their respective tensile properties. Properties for Material 1 are averages of tensile test results in longitudinal and transverse orientations of tank car plates, whereas properties for Material 2 were obtained from tensile tests in the longitudinal orientation. Material 1 appears to have slightly higher yield and ultimate tensile strengths than Material 2.

Table 1. Mechanical Properties for Normalized TC-128B

\begin{tabular}{|l|c|c|}
\hline & Material 1 & Material 2 \\
\hline Ultimate tensile strength & $90.6 \mathrm{ksi}$ & $87.3 \mathrm{ksi}$ \\
\hline Yield strength & $64.2 \mathrm{ksi}$ & $59.2 \mathrm{ksi}$ \\
\hline Elongation & $27.5 \%$ & $27 \%$ \\
\hline Reduction in area & $58 \%$ & $59 \%$ \\
\hline
\end{tabular}

Two impact tups were used in the tests: a blunt tup with a 0.5 inch wide contact surface (Figure 4), and a sharp tup with a 0.125 inch wide contact surface (Figure 5). Table 2 indicates combinations of BFCM test conditions in terms of impact tup, specimen material and specimen thickness.

This material is declared a work of the U.S. Government and is not subject to copyright protection in the United States. Approved for public release; distribution is unlimited. 


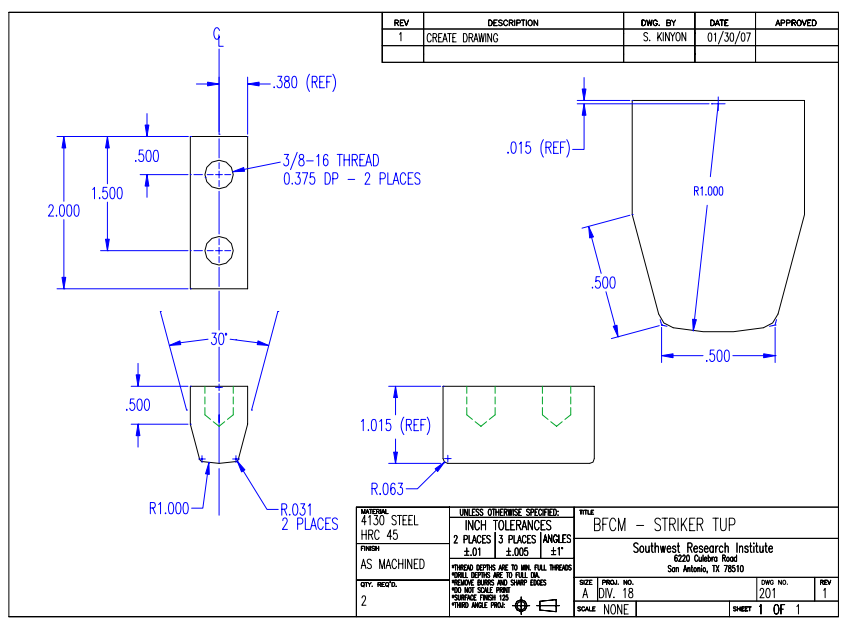

Figure 4. Blunt Impact Tup

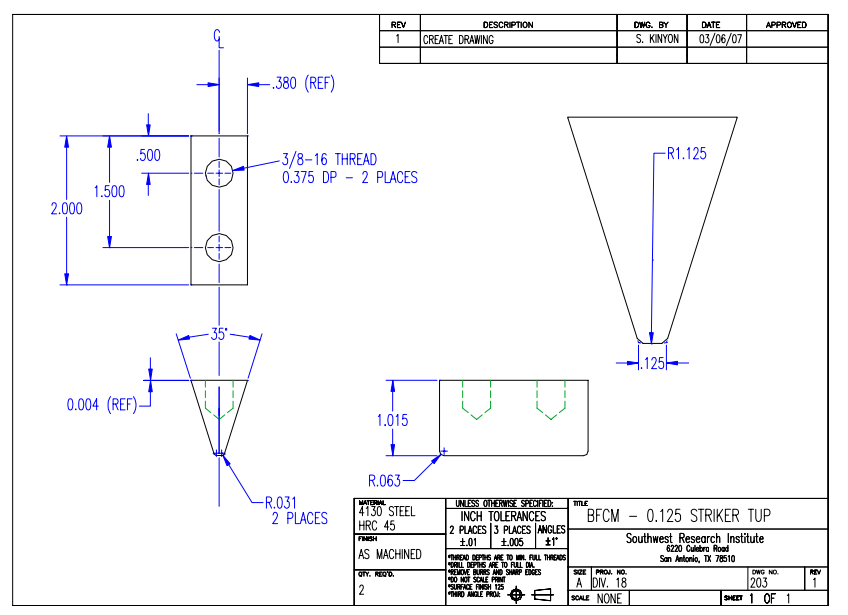

Figure 5. Sharp Impact Tup

Table 2. BFCM Test Combinations of Impact Tup, Specimen Material and Specimen Thickness

\begin{tabular}{|l|l|c|}
\hline & & Thickness (B, inches) \\
\hline Blunt tup & Material 1 & $0.827,0.625,0.5,0.375,0.25$ \\
\hline Sharp tup & Material 2 & $0.81,0.75,0.625,0.5,0.375,0.19$ \\
\hline
\end{tabular}

Figure 6 shows data from the BFCM tests conducted on specimens of varying thicknesses and using different impact strikers or tups [4]. The error bars represent the variability in the test data in terms of two standard deviations above and below the average for a given specimen thickness. The figure also shows regression curves of the test data for two different tups. The regression curves suggest that the BFCM fracture energy is related to the specimen thickness squared. Moreover, the test data indicate that more energy is required to fracture an unnotched specimen with the blunt tup than with the sharp tup.

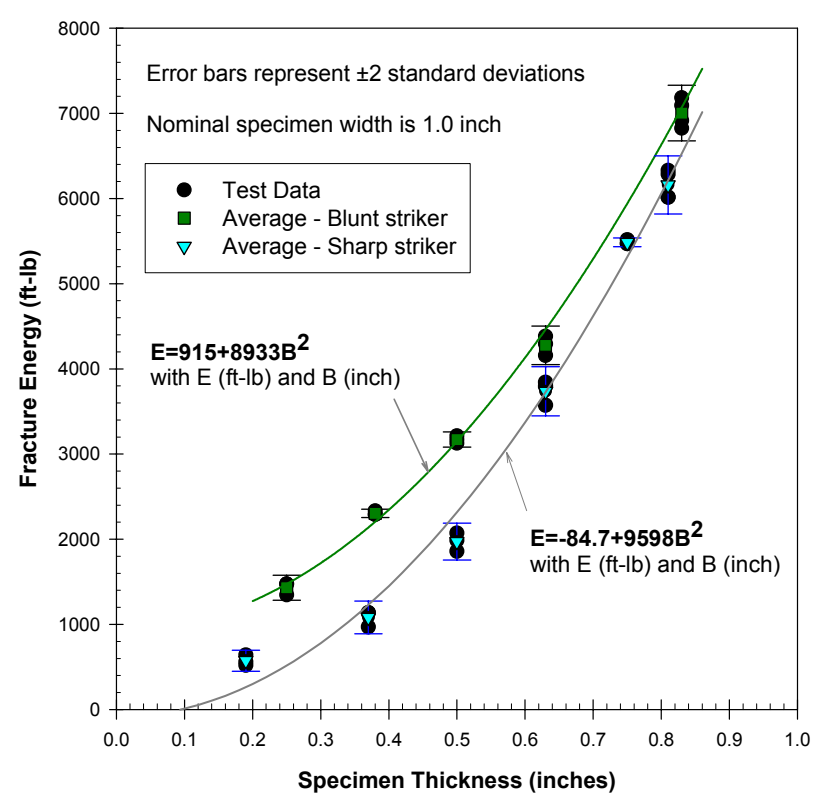

Figure 6. Fracture Energy of Normalized TC-128B Tank Car Steel as a Function of Specimen Thickness from BFCM Tests

\section{FRACTURE INITIATION CRITERIA AND STRESS TRIAXIALITY}

Different criteria were used in the nonlinear FEA to predict the onset of fracture in ductile metals such as steel: (1) prescribed maximum effective/equivalent strain to fracture, and (2) effective/equivalent fracture strain as a function of stress triaxiality. Stress triaxiality describes the portion of the stress tensor that is hydrostatic. For positive stress triaxiality, a stress state with high stress triaxiality approaches the completely hydrostatic state; with lower triaxiality stress states, the deviatoric component becomes a more significant portion of the stress tensor.

Mathematically, stress triaxiality is the ratio of mean stress to effective or von Mises equivalent stress, or

$$
\eta=\frac{\sigma_{m}}{\sigma_{e}}
$$

In terms of principal stresses, the mean stress and the effective stress are defined as

$$
\begin{aligned}
& \sigma_{m}=\frac{1}{3}\left(\sigma_{1}+\sigma_{2}+\sigma_{3}\right) \\
& \sigma_{e}=\sqrt{\frac{1}{2}\left[\left(\sigma_{1}-\sigma_{2}\right)^{2}+\left(\sigma_{2}-\sigma_{3}\right)^{2}+\left(\sigma_{3}-\sigma_{1}\right)^{2}\right]}
\end{aligned}
$$

This material is declared a work of the U.S. Government and is not subject to copyright protection in the United States. Approved for public release; distribution is unlimited. 
Mean or hydrostatic stress is associated with dilatation or the change in volume of a solid element. Effective or von Mises stress is directly related to octahedral shearing stress, which in turn is related to distortional energy or the energy to change the shape of a solid element. Therefore, a physical interpretation of stress triaxiality is that it is the ratio of volume change to shape change.

Figure 7 shows a schematic of the fracture initiation envelope for effective strain as a function of stress triaxiality [5]. Different modes of fracture are represented by different states of stress in terms of stress triaxiality. High stress triaxiality promotes microvoid growth and coalescence (Region I). Localized shear bands develop at negative or low levels of stress triaxiality, which may result in shear fracture (Region III). Intermediate levels of stress triaxiality may result in mixed mode fracture (Region II). The figure also shows a curve with a constant fracture initiation strain, which is intended to represent the prescribed maximum effective strain criterion that is independent of stress triaxiality.

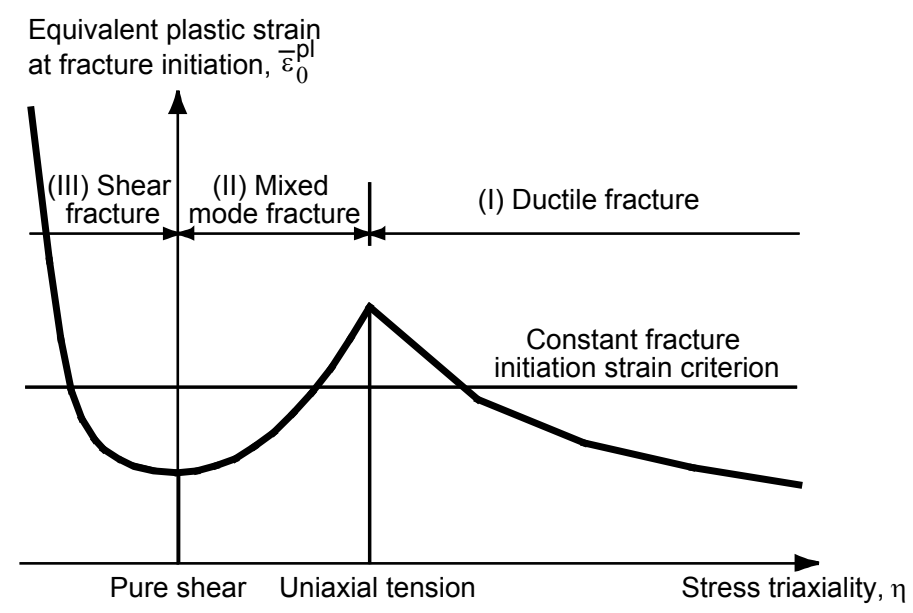

Figure 7. Schematic of Fracture Initiation Envelope Based on Stress Triaxiality

\section{FINITE ELEMENT ANALYSIS}

The FEA of the BFCM tests was conducted using the commercial software ABAQUS/Explicit [6]. Figure 8 shows a typical FEA model setup assuming quarter symmetries about $x$ $z$ and $y-z$ planes, where $x$-axis is along the longitudinal direction, $y$-axis along the width and $z$-axis along the thickness of a specimen. Model components include the impact tup with an initial impact velocity $v_{0}$, the specimen and a specimen fixture that holds the trapezoidal end of the specimen. The initial impact velocity $v_{0}$ was set at $14 \mathrm{mph}$, equivalent to the velocity gained by a mass at the end of a 52.45 inch long pendulum arm with a drop angle of 120 degrees. Impact tupspecimen and specimen-fixture contacts were defined and the coefficient of friction was set to be 0.57 .

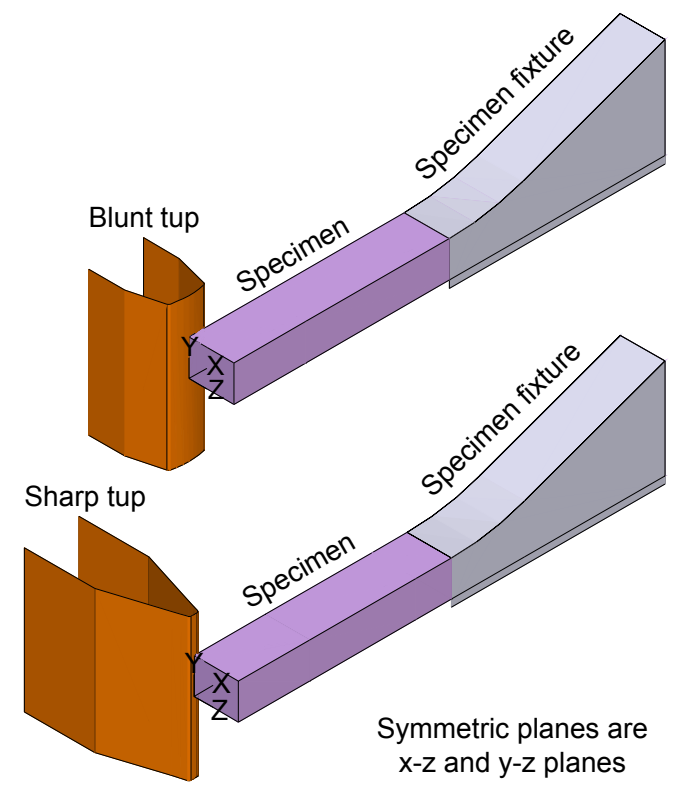

\section{Figure 8. Typical Quarter Symmetric Model of BFCM Tests with Blunt and Sharp Impact Tups}

Elastic properties for all specimens were assumed as: Young's modulus $E=30,000 \mathrm{ksi}$, and Poisson's ratio $v=0.3$. A Ramberg-Osgood relation for stress $(\sigma)$ versus strain $(\varepsilon)$ was adopted for plastic material behavior:

$\varepsilon=\sigma / E+(\sigma / K)^{n}$

where $K$ and $n$ are material constants that can be calibrated from the yield and ultimate tensile strengths with the assumption that the yield strength corresponds to the $0.2 \%$ offset (plastic) strain and the ultimate tensile strength corresponds to a total strain of $20 \%$.

Figure 9(a) shows a stress-strain $(\sigma-\varepsilon)$ relation employed in ABAQUS/Explicit for ductile metals up to complete material failure. Typical linear elastic and strain hardening responses are followed first. As the yield stress evolves to the peak level, an additional overall damage variable $D$ is introduced and damage initiates with $D=0$. The equivalent plastic strain at the onset of damage is denoted as $\bar{\varepsilon}_{0}^{\mathrm{pl}}$, and it can be a function of stress triaxiality $(\eta)$, strain rate, temperature, etc. Subsequently the yield stress softens and the elastic modulus degrades until the strain reaches $\bar{\varepsilon}_{\mathrm{f}}^{\mathrm{pl}}$, or the equivalent plastic strain at complete failure, where $D$ reaches the maximum degradation $D_{\max } \leq 1$. Finally, elements representing failed material points are removed from the model.

To deal with the spurious mesh dependence associated with strain softening or "strain localization," an element characteristic length $L_{\mathrm{e}}$ is introduced. For shell and 2-D elements, $L_{\mathrm{e}}$ is the square root of the integration point area, and for 3-D elements, it is the cubic root of the integration point

This material is declared a work of the U.S. Government and is not subject to copyright protection in the United States. Approved for public release; distribution is unlimited. 
volume [7]. Then a stress-displacement $(\sigma-u)$ relation shown in Figure 9(b) replaces the $\sigma-\varepsilon$ relation in Figure 9(a) in the material property definition, where $u$ is related to $\varepsilon$ by $L_{\mathrm{e}}$ such that $u=L_{\mathrm{e}} \varepsilon$. Following damage initiation, the equivalent plastic displacement $\bar{u}^{\mathrm{pl}}$ evolves according to $\dot{\bar{u}}^{\mathrm{pl}}=L_{\mathrm{e}} \dot{\bar{\varepsilon}}^{\mathrm{pl}}$ until it reaches $\bar{u}_{\mathrm{f}}^{\mathrm{pl}}$ at failure. In this study, displacement based damage evolution laws in ABAQUS/Explicit were selected and assigned a linear form. Thus the definition of a fracture initiation envelop in the $\eta$ - $\bar{\varepsilon}_{0}^{\mathrm{pl}}$ plane and that of an equivalent plastic displacement at complete failure $\left(\bar{u}_{\mathrm{f}}^{\mathrm{pl}}\right)$ completes the damage and failure material characterization.
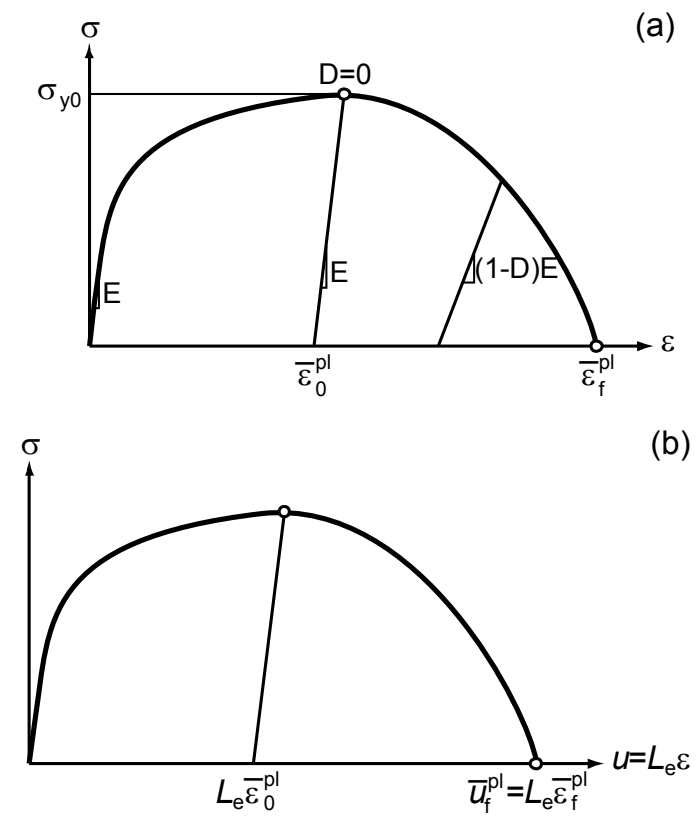

Figure 9. Illustration of ABAQUS Progressive Damage and Failure Modeling for Ductile Metals: (a) Typical StressStrain $(\sigma-\varepsilon)$ Relation, and (b) Stress-Displacement $(\sigma-u)$ Relation with the Introduction of an Element Characteristic Length $L_{\mathrm{e}}$

A stress triaxiality dependent fracture initiation envelop such as the one shown in Figure 7 can be approximated with the following analytical forms [8]

$\bar{\varepsilon}_{0}^{\mathrm{pl}}= \begin{cases}\infty, & \eta \leq-1 / 3 \\ C_{1} /(1+3 \eta), & -1 / 3<\eta \leq 0 \\ C_{1}+\left(C_{2}-C_{1}\right)\left(\eta / \eta_{0}\right)^{2}, & 0 \leq \eta \leq \eta_{0} \\ C_{2} \eta_{0} / \eta, & \eta_{0} \leq \eta\end{cases}$

where $C_{1}$ is equal to $\bar{\varepsilon}_{0}^{\mathrm{pl}}$ in pure shear $(\eta=0)$ and $C_{2}$ is equal to $\bar{\varepsilon}_{0}^{\mathrm{pl}}$ in uniaxial tension $\left(\eta=\eta_{0}\right)$. A so-called quick calibration method has been developed by Lee and Wierzbicki [8] to correlate $C_{1}, C_{2}$ and $\eta_{0}$ with the uniaxial tensile properties and was adopted in this study. However, while Lee and Wierzbicki [8] defined $\eta_{0}$ as the averaged stress triaxiality over the deformation history domain, in this study we treated $\eta_{0}$ as the instantaneous stress triaxiality in uniaxial tension such that $\eta_{0}=1 / 3$.

There has not been a known calibration method for the softening parameter, $\bar{u}_{\mathrm{f}}^{\mathrm{pl}}$, which measures the displacement capacity of a material beyond fracture initiation but prior to complete failure. In this study, $\bar{u}_{\mathrm{f}}^{\mathrm{pl}}$ was calculated as

$\bar{u}_{\mathrm{f}}^{\mathrm{pl}}=u_{1 \mathrm{f}}^{\mathrm{pl}}=L_{\mathrm{m}} \varepsilon_{1 \mathrm{f}}$

where $u_{1 \mathrm{f}}^{\mathrm{pl}}$ is the failure displacement in uniaxial tension, $\varepsilon_{1 \mathrm{f}}$ is the strain localization at failure in uniaxial tension and $L_{\mathrm{m}}$ is a material characteristic length over which $\varepsilon_{1 \mathrm{f}}$ is measured. With the limited test data available, $\varepsilon_{1 \mathrm{f}}$ was defined as the elongation in uniaxial tension and $L_{\mathrm{m}}$ the gauge length over which the elongation was measured.

The calibrated plastic and damage/failure material parameters using the data in Table 1 are summarized in Table 3. The fracture initiation envelopes derived for both materials are shown in Figure 10.

Table 3. Calibrated Material Parameters for Normalized TC-128B Materials

\begin{tabular}{|l|c|c|c|c|c|c|}
\hline & $K(\mathrm{ksi})$ & $n$ & $\eta_{0}$ & $C_{1}$ & $C_{2}$ & $\bar{u}_{\mathrm{f}}^{\mathrm{pl}}$ (inch) \\
\hline Material 1 & 102.3 & 13.35 & $1 / 3$ & 0.223 & 0.868 & 0.275 \\
\hline Material 2 & 100.2 & 11.82 & $1 / 3$ & 0.256 & 0.892 & 0.27 \\
\hline
\end{tabular}

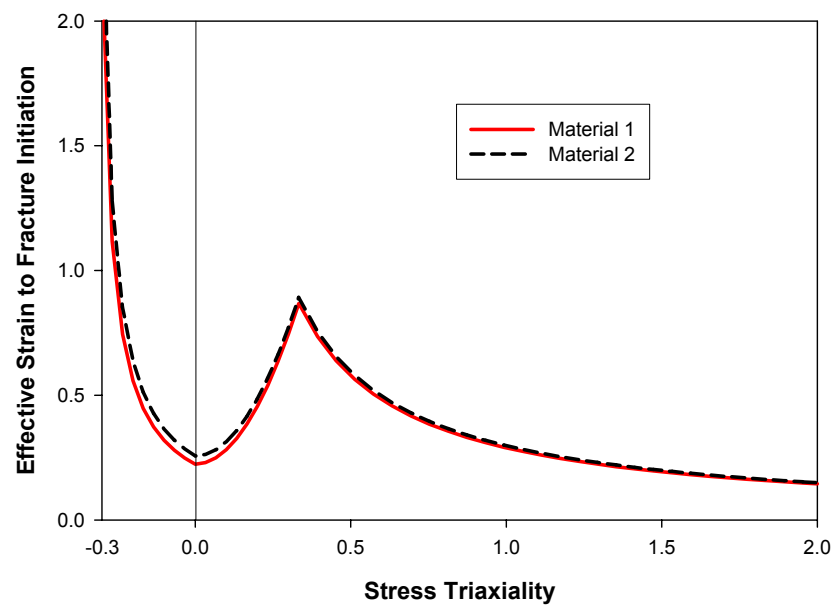

Figure 10. Stress Triaxiality Based Fracture Initiation Envelops for TC-128 Tank Car Steel

This material is declared a work of the U.S. Government and is not subject to copyright protection in the United States. Approved for public release; distribution is unlimited. 
Figure 11 compares the post-failure shape of a BFCM specimen obtained from the FEA and a test. The deformed shapes look similar between the analysis result and the test photograph. An output of interest from both tests and simulations is the impact energy needed to fail a specimen, which was calculated as

$E=\frac{1}{2} m\left(v^{2}-v_{0}^{2}\right)$

where $m=2378$ pounds is the impactor mass, $v_{0}=14 \mathrm{mph}$ is the initial impact velocity, and $v$ is the post-impact velocity after the impactor completely detaches from the specimen.

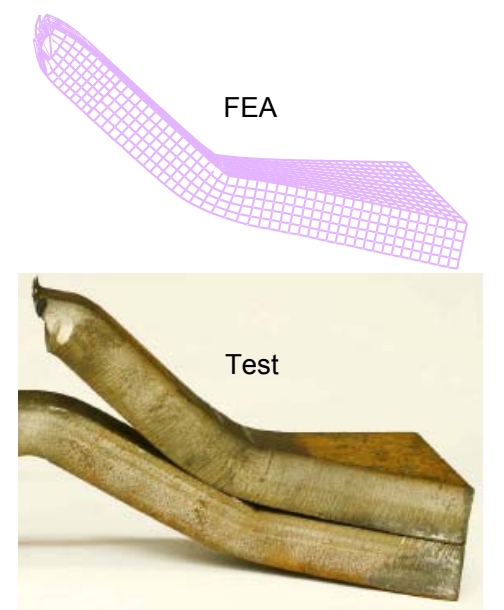

Figure 11. Deformed Shapes of BFCM Specimen from FEA and Test

Both continuous and tied solid elements were employed in the FE models of the BFCM specimens, and mesh sensitivity was examined by varying the number of solid element layers through the thickness while keeping the solid element aspect ratios close to 1:1:1. The main advantage of employing the tied solid element technique is that low to moderate computational cost can be maintained when finer mesh is needed in the relatively small impact zone but not necessary in the rest of the specimen. Simulations of the test combination \{Blunt tup, Material $1, \mathrm{~B}=0.827$ inches $\}$ were selected for the mesh sensitivity study. Figure 12 plots the impact energy calculated according to Equation (7) versus the number of through-thethickness element layers. The tied and continuous solid element methods yield very comparable results. Furthermore, the FEA results in terms of impact energy appear to converge with six layers of through-the-thickness elements. As a result, in this study the number of elements through the specimen thickness was set to be six, and tied solid elements were used.

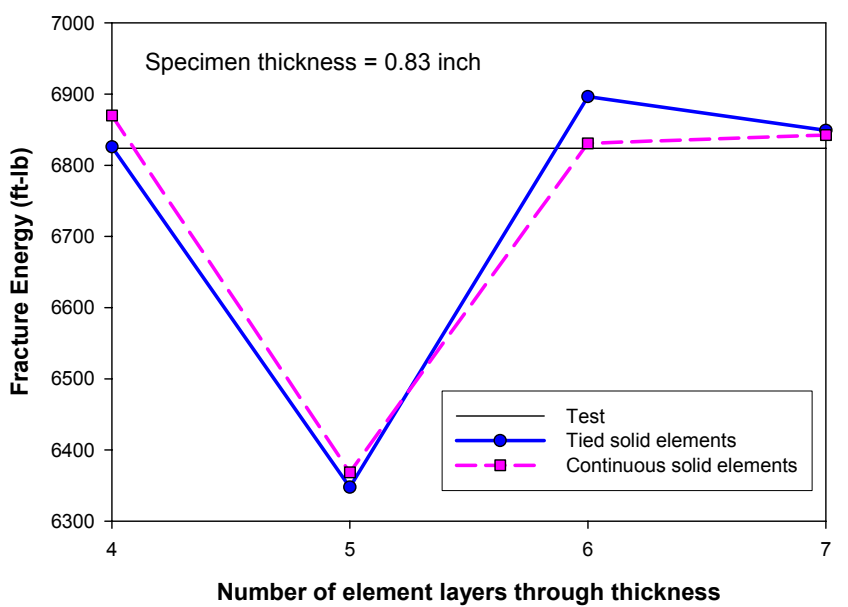

Figure 12. Convergence of Impact Energy with Mesh Refinement

\section{RESULTS}

Figure 13 compares the results from the FEA using the maximum effective strain criterion with the test data for the blunt impactor. The constant fracture initiation strain in the analyses was assumed to be $20 \%$, whereas the plastic $(K, n)$ and softening parameters $\left(\bar{u}_{\mathrm{f}}^{\mathrm{pl}}\right)$ were the same as those in Table 3. This approach underestimates the impact energy for the thicker specimens and overestimates it for the thinner ones.

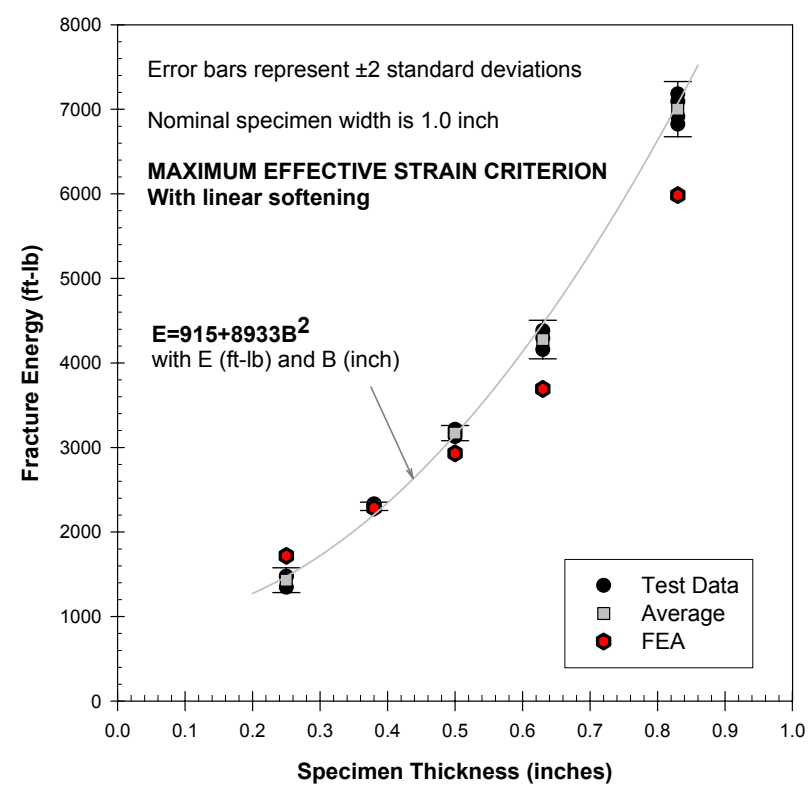

Figure 13. Comparison Between Tests and Analyses with Maximum Effective Strain Criterion for Blunt Tup

This material is declared a work of the U.S. Government and is not subject to copyright protection in the United States. Approved for public release; distribution is unlimited. 
Similarly, Figure 14 shows the comparison between test and analysis using the criterion based on stress triaxiality for the blunt impactor. The close agreement between the test data and the results from the analysis is self-evident especially for the thicker specimens.

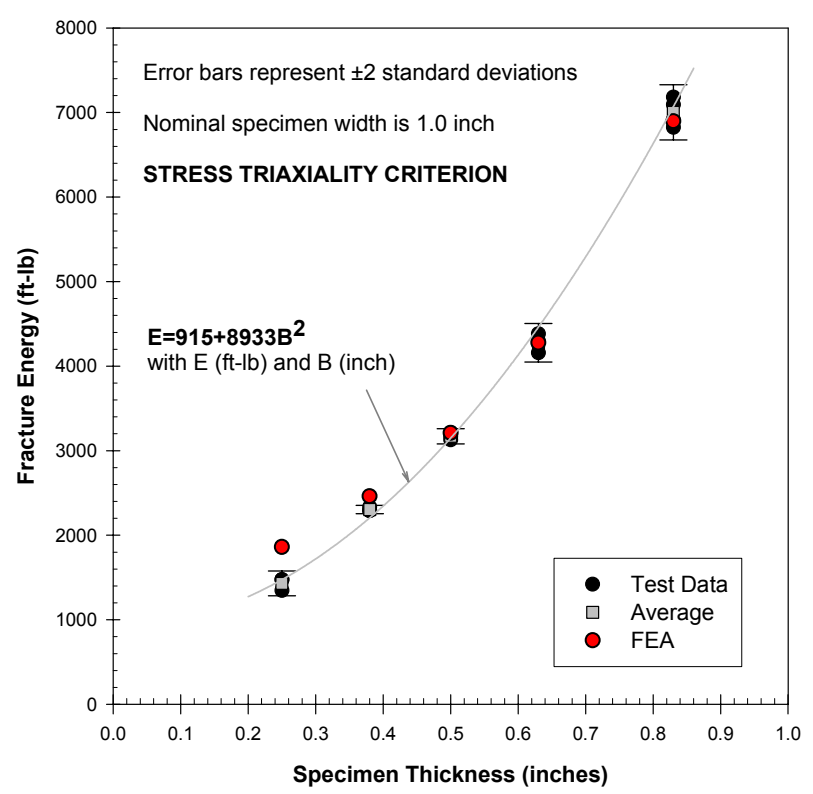

Figure 14. Comparison Between Tests and Analyses with Stress Triaxiality Based Criterion for Blunt Tup

Figure 15 shows the comparison between test and analysis using the stress triaxiality based criterion with the sharp tup. The figure shows that test data and results from the analysis are within reasonable agreement.

\section{PARAMETRIC STUDIES}

Although parameters calibrated mainly according to Table 1 and Table 3 were used in the above analyses, it was of interest to investigate the effects of the parameter changes. Four categories of parameters were identified: plasticity (yield and ultimate tensile strengths), fracture initiation $\left(C_{1}\right.$ and $\left.C_{2}\right)$, softening $\left(\bar{u}_{\mathrm{f}}^{\mathrm{pl}}\right)$ and contact (coefficient of friction). Sensitivity of the predicted impact energy to changes in these parameters is summarized in Table 4 for simulations again of the test combination \{Blunt tup, Material 1, B=0.827 inches\}.

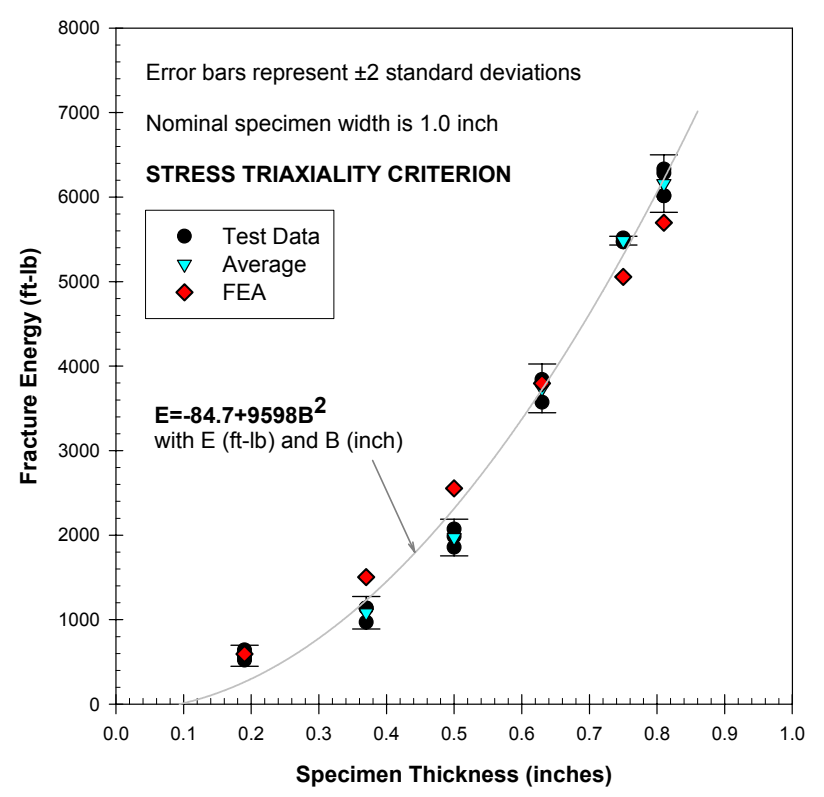

Figure 15. Comparison Between Tests and Analyses with Stress Triaxiality Based Criterion for Sharp Tup

In the plasticity category, the parameters were changed to those of a TC128-B material with lower yield and ultimate strengths. In the fracture initiation category, the $C_{1}$ and $C_{2}$ parameters calibrated according to data from a different source (normalized TC128-B steel tested in T-L orientation at $0^{\circ} \mathrm{F}$ [9]) were used. The failure displacement $\bar{u}_{\mathrm{f}}^{\mathrm{pl}}$ was varied by $\pm 100 \%$ relative to the baseline. Last, two other commonly used coefficients of friction for contacts between steel and steel, 0 and 0.16 , were examined in addition to the baseline value of 0.57 . Only one category of parameters was changed each time while the remaining parameters retained their baseline Material 1 values.

Table 4. Percent Changes in Impact Energy with Key Model Parameter Changes

\begin{tabular}{|c|c|c|c|c|}
\hline Parameter & $\begin{array}{c}\text { Baseline } \\
\text { value }\end{array}$ & $\begin{array}{l}\text { New } \\
\text { value }\end{array}$ & $\begin{array}{l}\text { Change in } \\
\text { parameter }\end{array}$ & \begin{tabular}{|c|} 
Change in \\
impact energy
\end{tabular} \\
\hline Yield str & $64.2 \mathrm{ksi}$ & $50 \mathrm{ksi}$ & 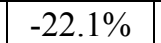 & \multirow[b]{2}{*}{$-15.0 \%$} \\
\hline \begin{tabular}{|c|} 
Ultimate \\
tensile strength
\end{tabular} & $90.6 \mathrm{ksi}$ & $81 \mathrm{ksi}$ & $-10.5 \%$ & \\
\hline$C_{1}$ & 0.223 & 0.345 & $54.7 \%$ & \multirow{2}{*}{$3.1 \%$} \\
\hline$C_{2}$ & 0.868 & 0.977 & $12.6 \%$ & \\
\hline \multirow{2}{*}{$\bar{u}_{\mathrm{f}}^{\mathrm{pl}}$} & \multirow{2}{*}{$\begin{array}{l}0.275 \\
\text { inch. }\end{array}$} & 0 & $-100.0 \%$ & $-30.9 \%$ \\
\hline & & 0.55 inch. & $100.0 \%$ & $19.5 \%$ \\
\hline \multirow{2}{*}{$\begin{array}{c}\text { Coefficient of } \\
\text { friction }\end{array}$} & \multirow{2}{*}{0.57} & 0 & $-100.0 \%$ & $-8.6 \%$ \\
\hline & & 0.16 & $-71.9 \%$ & $-5.8 \%$ \\
\hline
\end{tabular}

This material is declared a work of the U.S. Government and is not subject to copyright protection in the United States. Approved for public release; distribution is unlimited. 
It may be concluded from Table 4 that (1) the plasticity parameters have the most significant effect on model predictions, as the percent changes in yield and ultimate strengths lead to the same order of percent changes in the predicted impact energy, (2) damage/failure parameters, especially $C_{2}$ and $\bar{u}_{\mathrm{f}}^{\mathrm{pl}}$, have secondary but considerable effects, and (3) the effect of the coefficient of friction is much less significant.

\section{CONCLUDING REMARKS}

Nonlinear FEA with different failure criteria has been conducted to simulate tests on unnotched Charpy specimens and to calculate fracture energies. The FEA with a material failure criterion based on stress triaxiality provided excellent agreement with the test data for different impacting strikers.

Moreover, the agreement between test and analysis provides a benchmark for which the failure criterion can be applied to other impact loading scenarios. For example, FEA using the stress triaxiality criterion to examine the failure of a railroad tank car under impact loading will be described in a future communication.

\section{ACKNOWLEDGMENTS}

The Federal Railroad Administration (FRA), Office of Research \& Development (R\&D) sponsored the work described in this paper. Ms. Claire Orth is the Chief of the Equipment and Operating Practices Division. Mr. Francisco Gonzalez is the FRA project manager for research on railroad tank cars. Mr. Eloy Martinez of FRA's R\&D also provides technical direction to the project. Discussions with Professor A. Benjamin Perlman are gratefully appreciated and acknowledged.

\section{REFERENCES}

[1] Phillips, E.A., Olsen, L., 1972: "Final Phase 05 Report on Tank Car Head Study," RPI-AAR Tank Car Safety Research and Test Project, RA-05-17.

[2] Coltman, M., Hazel, M., 1992: "Chlorine Tank Car Puncture Resistance Evaluation," Final Report, DOT/FRA/ORD-92/11.

[3] Siewert, T.A., Manahan, Sr., M.P., Eds. 2000: Pendulum Impact Testing: A Century of Progress, STP 1380, American Society for Testing and Materials, West Conshohocken, PA.

[4] McKeighan, P., 2007: "Mechanical Properties of Tank Car Steels Retired from the Fleet," Southwest Research Institute Report to the Volpe Center.

[5] Bao, Y., Wierzbicki, T., 2004: "On fracture locus in the equivalent strain and stress triaxiality space," International Journal of Mechanical Sciences 46, 81-98.

[6] ABAQUS Inc., 2006: ABAQUS Analysis User's Manual.

[7] ABAQUS Inc., 2006: ABAQUS Keywords Reference Manual.
[8] Lee, Y.W., Wierzbicki, T., 2004: "Quick Fracture Calibration for Industrial Use," Massachusetts Institute of Technology, Impact \& Crashworthiness Laboratory Report No. 115.

[9] Hicho, G.E., D.E. Harne, 1991: "Mechanical Properties and Fracture Toughness of AAR TC-128B Steel in the Normalized, and Normalized and Stress Relieved Conditions," NISTIR 4660, Report No. 24, National Institute of Standards and Technology.

This material is declared a work of the U.S. Government and is not subject to copyright protection in the United States. Approved for public release; distribution is unlimited. 